Impact of Bordetella pertussis Exposures on a Massachusetts Tertiary Care Medical System Author(s): Iva Zivna, MD, Diana Bergin, MS, APRN BC, Joanne Casavant, MS, APRN BC, Sally Fontecchio, RN, BSNEd, CIC, Susan Nelson, RN, MSPH, CIC, Anita Kelley , RN, MSN, CIC, Sandra Mathis , RN, MPH, CIC, Zita Melvin , RN, BSN, CIC, Rosemarie Erlichman , RN, BSN, CIC , Richard T. Ellison III and MD

Source: Infection Control and Hospital Epidemiology, Vol. 28, No. 6 (June 2007), pp. 708-712 Published by: Cambridge University Press on behalf of Society for Healthcare Epidemiology of America

Stable URL: http://www.jstor.org/stable/10.1086/518352

Accessed: 10-12-2015 16:39 UTC

Your use of the JSTOR archive indicates your acceptance of the Terms \& Conditions of Use, available at http://www.jstor.org/page/ info/about/policies/terms.jsp

JSTOR is a not-for-profit service that helps scholars, researchers, and students discover, use, and build upon a wide range of content in a trusted digital archive. We use information technology and tools to increase productivity and facilitate new forms of scholarship. For more information about JSTOR, please contact support@jstor.org. 
INFECTION CONTROL AND HOSPITAL EPIDEMIOLOGY JUNE 2007, VOL. 28, NO. 6

\title{
Impact of Bordetella pertussis Exposures on a Massachusetts Tertiary Care Medical System
}

\author{
Iva Zivna, MD; Diana Bergin, MS, APRN BC; \\ Joanne Casavant, MS, APRN BC; Sally Fontecchio, RN, BSNEd, CIC; \\ Susan Nelson, RN, MSPH, CIC; Anita Kelley, RN, MSN, CIC; Sandra Mathis, RN, MPH, CIC; \\ Zita Melvin, RN, BSN, CIC; Rosemarie Erlichman, RN, BSN, CIC; Richard T. Ellison III, MD
}

\begin{abstract}
овjестіve. To assess the impact of outbreaks of Bordetella pertussis infection on a tertiary care medical system.
DESIGN. Retrospective study.

Setting. Academic tertiary care medical center and affiliated ambulatory care settings.

suвjестs. All patients and healthcare workers (HCWs) who were in close contact with patients with laboratory-confirmed cases of $B$. pertussis infection from October 1, 2003, through September 30, 2004.

intervention. Direct and indirect medical center costs were determined, including low and high estimates of time expended in the evaluation and management of exposed patients and HCWs during outbreak investigations of laboratory-confirmed cases of $B$. pertussis infection.

RESULTS. During this period, 20 primary and 3 secondary laboratory-confirmed cases of $B$. pertussis infection occurred, with 2 primary pertussis cases and 1 secondary case occurring in HCWs. Outbreak investigations prompted screening of 353 medical center employees. Probable or definitive exposure was identified for $296 \mathrm{HCWs}$, and 287 subsequently received treatment or prophylaxis for B. pertussis infection. Direct medical center costs for treatment and prophylaxis were $\$ 13,416$ and costs for personnel time were $\$ 19,500-\$ 31,190$. Indirect medical center costs for time lost from work were $\$ 51,300-\$ 52,300$. The total cost of these investigations was estimated to be $\$ 85,066-\$ 98,456$.
\end{abstract}

CONCLUSIONS. Frequent B. pertussis exposures had a major impact on our facility. Given the impact of exposures on healthcare institutions, routine vaccination for HCWs may be beneficial.

Infect Control Hosp Epidemiol 2007; 28:708-712

Despite effective childhood immunization, pertussis remains endemic in the United States. The incidence of pertussis has remained high in children $1-5$ years old ${ }^{1,2}$; however, evidence is increasing that Bordetella pertussis is also an important pathogen among adolescent and adult populations. ${ }^{3-9}$ Furthermore, it is apparent that adolescents and adults with pertussis represent a significant source for transmission of $B$. pertussis to infants younger than 4 months, resulting in increasing morbidity and mortality in this age group. ${ }^{10}$

Pertussis is a remarkably contagious disease, transmitted by aerosolized droplets, with secondary attack rates of $50 \%$ $100 \%$ in close contacts, depending on the nature of the exposure. ${ }^{11,12}$ It thus represents a major challenge in healthcare settings, and during the last decade, numerous nosocomial outbreaks of pertussis have been reported. ${ }^{13-18} \mathrm{Un}$ fortunately, these outbreaks not only represent a medical risk for patients but also can significantly strain healthcare institution resources. In this retrospective study, we sought to determine the impact of $B$. pertussis outbreaks on our healthcare system during 1 fiscal year, at a time when there was a notable increase in pertussis cases in our state.

\section{METHODS}

\section{Study Design and Period}

A pertussis investigation was initiated at the University of Massachusetts Memorial Medical Center (UMMMC) whenever a laboratory-confirmed case of pertussis was recognized. For this report, all data from the UMMMC infection control and employee health departments were retrospectively reviewed to identify the number of screened, exposed, and treated patients and healthcare workers (HCWs) who un-

From the Division of Infectious Diseases, Department of Medicine, University of Massachusetts Medical School (I.Z., R.T.E.), and the Division of Infectious Diseases and Immunology, University of Massachusetts Memorial Medical Center (D.B., J.C., S.F., S.N., A.K., S.M., Z.M., R.E., R.T.E.), Worcester.

Received September 21, 2006; accepted November 8, 2006; electronically published May 8, 2007.

(C) 2007 by The Society for Healthcare Epidemiology of America. All rights reserved. 0899-823X/2007/2806-0012\$15.00. DOI: 10.1086/518352 
derwent evaluation from October 1, 2003, through September 30, 2004.

\section{Definitions}

Pertussis cases were defined based on the criteria of the Massachusetts Department of Public Health. ${ }^{19}$ A clinical case of pertussis was defined as an acute cough illness that lasted 14 days or longer in a person with at least 1 symptom characteristic of pertussis (eg, paroxysmal cough, inspiratory whoop, or posttussive vomiting) or cough that persisted for more than 14 days during an outbreak. A confirmed case of pertussis met the clinical case definition and was confirmed if culture of a nasopharyngeal swab specimen or serologic analysis was positive for $B$. pertussis or if there was epidemiologic linkage to a laboratory-confirmed case. A person with a confirmed case of $B$. pertussis was considered to be infectious from 1 week before until 3 weeks after the onset of typical paroxysmal cough.

Screening was performed by reviewing the work schedules of all healthcare employees who were identified as having a potential exposure to the patient or HCW with confirmed pertussis. All individuals who were potentially exposed were questioned about exposure to the index patient and whether they had any signs or symptoms suggestive of pertussis. Employees were considered to be exposed to a confirmed case of pertussis if they had direct face-to-face contact with the case subject while not wearing a surgical mask; spent more than 10 hours per week in the same general work station or area with the case subject; came into mucosal contact with the respiratory, oral, or nasal secretions of an individual with confirmed pertussis; or were present and not wearing a surgical mask during a cough-inducing procedure for an individual with confirmed pertussis.

Exposed screened HCWs were the subset of screened HCWs who reported a history of exposure to a patient or other HCW with pertussis. Unexposed screened HCWs were the subset of screened HCWs without exposure to an index case of pertussis.

The time needed for screening and exposure evaluation was assessed retrospectively by interviewing all personnel assigned to screening- and exposure-related activities. Because there was variation in the estimates of the time taken for these investigations, high and low time estimates for each of the aspects of the outbreak investigation were developed, as follows. For the infection control department, the time for the initial diagnostic workup was 2 hours plus 0.05 hour (low estimate) or 0.1 hour (high estimate) per screened HCW, and for the unit manager, the time for the initial diagnostic workup was 2 hours plus 0.25 hour or 0.5 hour per screened HCW. For the employee health department, the time spent was 2 hours plus 0.25 hour or 0.5 hour per screened unexposed HCW and was 2 hours plus 0.5 or 0.75 hour per 0.5 hour per screened exposed HCW. For screened HCWs, the time lost from work was 0.1 hour or 0.25 hour per screened unexposed HCW and was 0.5 hour or 0.75 hour per screened exposed HCW. All screened symptomatic HCWs who had been exposed to a patient with a confirmed case of B. pertussis infection within the previous 21 days were evaluated by culture of a nasopharyngeal swab specimen and placed on medical leave for 5 days while undergoing therapy with antibiotics.

Direct medical center costs associated with pertussis outbreaks were calculated as the cost of antibiotics needed for prophylaxis or therapy for exposed medical center employees and the cost of the time of designated personnel assigned to these outbreaks. The cost of nasopharyngeal culture, including the cost of swabs, laboratory supplies, and the time of UMMMC laboratory personnel needed for evaluation, were estimated to be $\$ 15-\$ 25$ per culture.

Indirect medical center costs were calculated as the number of hours of lost employee time associated with the process of screening, evaluation of exposures, and work missed by exposed HCWs placed on temporary medical leave. These costs included the cost of the replacement worker needed to take the place of a symptomatic HCW on medical leave.

\section{RES ULTS}

From October 1, 2003, through September 30, 2004, there were 20 primary and 3 secondary laboratory-confirmed cases of pertussis at UMMMC (Table). Two primary cases and 1 secondary case occurred among employees of our facility. The source of infection for the 2 primary cases among HCWs could not be identified. Outbreak investigations prompted the screening of 353 HCWs who were potentially in close contact with individuals who had laboratory-confirmed cases of pertussis. Exposure was identified for 296 screened HCWs, and 287 of them subsequently received treatment or prophylaxis for pertussis infection. This resulted in an estimated 1,034-1,118 hours of time lost from work and 389-604 hours of intensive work by staff in infection control, employee health, and unit management.

Direct medical center costs included treatment and prophylaxis (287 prescriptions), which cost $\$ 13,416$, and the estimated time of the personnel assigned to these outbreaks (389-604 hours) at a cost of $\$ 19,500-\$ 31,190$. The estimated cost of laboratory testing (23 nasal swab specimen cultures) was unremarkable at $\$ 330-\$ 550$, and serologic testing (9 B. pertussis immunoglobulin $\mathrm{G}$ antibody tests) was performed by the Massachusetts Department of Public Health laboratory at no cost to our institution but with an estimated cost of $\$ 520-\$ 800$.

Indirect medical center costs included 23 exposed and symptomatic HCWs being placed on medical leave, resulting in 880 hours of lost time from work. An additional 154-238 hours were included in time missed from work for screening or evaluation of exposure, making the estimated total cost of time lost from work $\$ 51,300-\$ 52,300$.

The cost to UMMMC of these investigations is estimated to have been $\$ 84,546-\$ 97,656$ (Table). Including the cost of 


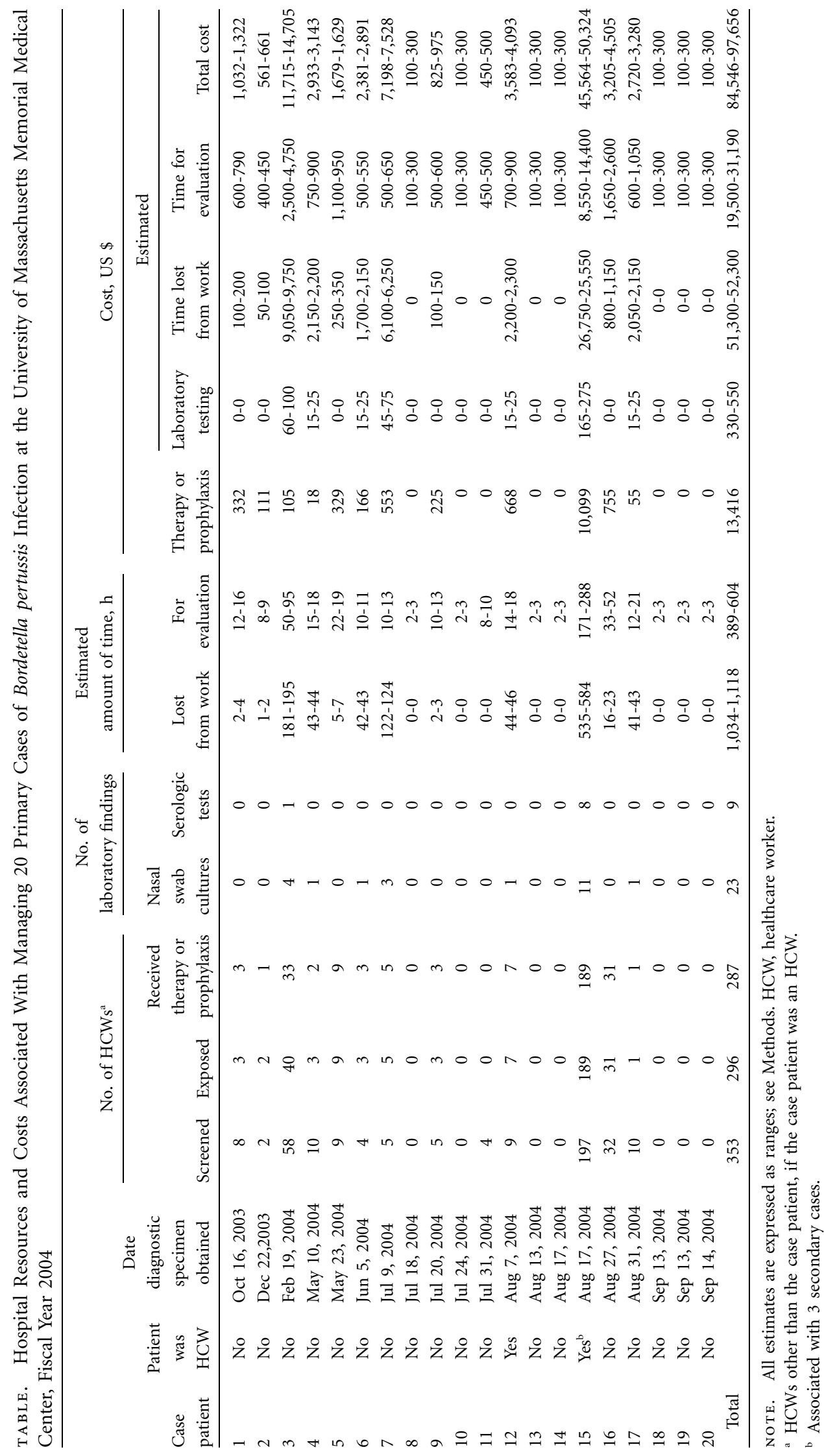


the serologic testing, the estimated total cost of the investigations was $\$ 85,066-\$ 98,456$.

\section{DISCUSSION}

After introduction of the whole-cell pertussis vaccine in 1947, the incidence of pertussis significantly decreased. Still, the infection has remained endemic, with cyclic increases noted every 2-5 years, suggesting that the vaccine has controlled the disease but not eradicated circulation of the pathogen. In fact, the number of cases of $B$. pertussis infection in the United States has been rising, although vaccine efficacy has appeared to be good. ${ }^{1,10,20}$ Of note, numerous states reported particularly high levels of pertussis during calendar year 2004.

The transmissibility of pertussis is highest at the catarrhal stage before the onset of paroxysmal cough, and it gradually decreases until it is negligible approximately 3 weeks after the onset of symptoms. The symptoms of pertussis may vary in severity from a mild upper respiratory tract infection to the full-blown syndrome, and rapid diagnostic testing is not readily available. Also, many cases of pertussis occur in previously vaccinated persons because of waning immunity. All of these factors contribute to the difficulty of managing pertussis in healthcare settings, locations where infection control measures need to be especially rigorous to protect individuals at high risk of complications.

In our institution, all persons with suspected cases of pertussis were promptly isolated and placed under droplet precautions until they had completed 5 days of an appropriate course of antibiotic therapy. Prompt epidemiologic investigations were initiated to identify exposed HCWs and patients, and as appropriate, were performed in coordination with the Massachusetts Department of Public Health. All symptomatic HCWs exposed to individuals with confirmed cases of $B$. pertussis infection during the period of communicability (21 days or less after the onset of cough) were tested and excluded from work until they had completed 5 days of an appropriate course of antibiotic therapy; if they were not treated, they were excluded from work for 3 weeks after cough onset. All asymptomatic exposed HCWs who did not receive antibiotic prophylaxis were excluded from work for 21 days after their last exposure or, if the time of exposure was unknown, for 21 days after the onset of the last confirmed case of pertussis in the facility. ${ }^{21}$

Our approach of investigating all cases of pertussis for potential transmission within the institution may be considered relatively aggressive. However, during the past several years, an increasing number of pertussis outbreaks have occurred in healthcare facilities, ${ }^{14-16}$ and the approach that was undertaken was in accordance with guidelines from the Massachusetts Department of Public Health. ${ }^{19}$

In this study, we found that implementing these guidelines for the evaluation of $B$. pertussis exposures had a major impact on our facility. The impact on the infection control, employee health, and unit management staff was particularly significant, functionally representing 3-6 weeks of full-time effort for 1 infection control staff member, 1 employee health staff member, and 1 unit manager.

The direct medical center costs were estimated to be $\$ 64,716-\$ 65,716$, which does not include the indirect medical center cost of time lost from work because of screening and evaluation of exposed HCWs. Having HCWs placed on medical leave also represented a significant expense.

The retrospective nature of this study may have led to overestimation or underestimation of the time and expense involved in screening and exposure evaluation. We tried to overcome this limitation by developing high and low time estimates for each aspect of the outbreak investigations. Additionally, only partial data were available on patient exposures, because several of the exposures took place in waiting areas and it was not possible to identify all of the exposed individuals. However, a minimum of 200 patients were determined to have been exposed, and they each received a letter about potential exposure.

Given the increasing number of pertussis cases being seen nationally and the impact of pertussis exposures on healthcare institutions, routine vaccination for HCWs may be beneficial in decreasing the number of HCWs who develop the disease. ${ }^{22}$ However, as highlighted in this study, many of the exposures in healthcare settings are linked to illness in patients. Because the institutional expense for the work involved in outbreak investigations is significant, a key area for future study is determining whether immunizing HCWs can obviate the need for antibiotic prophylaxis or exclusion from work in this population.

\section{ACKNOWLEDGMENTS}

Potential conflicts of interest. All authors report no conflicts of interest relevant to this article.

Address reprint requests to Iva Zivna, MD, Division of Infectious Diseases and Immunology, University of Massachusetts Memorial Medical Center, 55 Lake Ave. N., Worcester, MA 01655 (zivnai@ummhc.org).

Presented in part: 15th Annual Scientific Meeting of the Society for Healthcare Epidemiology of America; Los Angeles, California; April 9-12, 2005 (Abstract 191).

\section{REFERENCES}

1. Tanaka M, Vitek CR, Pascual FB, Bisgard KM, Tate JE, Murphy TV. Trends in pertussis among infants in the United States, 1980-1999. JAMA 2003; 290:2968-2975.

2. Christie C, Marx M, Merchant C, Reising SF. The 1993 epidemic of pertussis in Cincinnati: resurgence of disease in a highly immunized population of children. N Engl J Med 1994; 331:16-21.

3. Senzilet LD, Halperin SA, Spika JS, Alagaratnem M, Morris A, Smith B; Sentinel Health Unit Surveillance System Pertussis Working Group. Pertussis is a frequent cause of prolonged cough illness in adults and adolescents. Clin Infect Dis 2001; 32:1691-1697.

4. Birkebaek NH, Kirstiansen M, Seefeldt T, et al. Bordetella pertussis and chronic cough in adults. Clin Infect Dis 1999; 29:1239-1242.

5. He Q, Viljanen MK, Arvilomni H, Aittanen B, Mertsola J. Whooping 
cough caused by Bordetella pertussis and Bordetella parapertussis in an immunized population. JAMA 1998; 280:635-637.

6. Nennig ME, Shinefield HR, Edwards KM, Black SB, Fireman BH. Prevalence and incidence of adult pertussis in an urban population. JAMA 1996; 275:1672-1674.

7. Wright SW, Edwards KM, Decker MD, Zeldin MH. Pertussis infection in adults with persistent cough. JAMA 1995; 273:1044-1046.

8. Yih WK, Lett SM, des Vignes FN, Garrison KM, Sipe PL, Marchant CD. The increasing incidence of pertussis in Massachusetts adolescents and adults, 1989-1998. J Infect Dis 2000; 182:1409-1416.

9. Strebel P, Nordin JD, Edwards K, et al. Population-based incidence of pertussis among adolescents and adults, Minnesota, 1995-1996. J Infect Dis 2001; 183:1353-1359.

10. Vitek CR, Pascual FB, Baughman AL, Murphy TV. Increase in deaths from pertussis among young infants in the United States in the 1990s. Pediatr Infect Dis J 2003; 22:628-634.

11. Schellekens J, Wirsing von Konig CH, Gardner P. Pertussis sources of infection and routes of transmission in the vaccination era. Pediatr Infect Dis J 2005; 24(5suppl):S19-S24.

12. Wirsing von Konig CH, Postels-Multani S, Bock HL, Schmitt HJ. Pertussis in adults: frequency of transmission after household exposure. Lancet 1995; 346:1326-1329.

13. Steketee RW, Wassilak SG, Adkins WN Jr, et al. Evidence for a high attack rate and efficacy of erythromycin prophylaxis in a pertussis outbreak in a facility for the developmentally disabled. J Infect Dis 1988; $157: 434-440$

14. Bassinet L, Matrat M, Njakempo E, Aberrane S, Housset B, Guiso N. Nosocomial pertussis outbreak among adult patients and healthcare workers. Infect Control Hosp Epidemiol 2004; 25:995-997.

15. Ward A, Caro J, Bassinet L, Housset B, O’Brien JA, Guiso N. Health and economic consequences of an outbreak of pertussis among health- care workers in a hospital in France. Infect Control Hosp Epidemiol 2005, 26:288-292.

16. Boulay BR, Murray CJ, Ptak J, Kirkland KB, Montero J, Talbot EA. An outbreak of pertussis in a hematology-oncology care unit: implications for adult vaccination policy. Infect Control Hosp Epidemiol 2006; 27:92-95.

17. Fisher MC, Long SS, McGowan KL, Kaselis E, Smith DG. Outbreak of pertussis in a residential facility for handicapped people. J Pediatr 1989; 114:934-939.

18. Addiss DG, Davis JP, Meade BD, et al. A pertussis outbreak in a Wisconsin nursing home. J Infect Dis 1991; 164:704-710.

19. Massachusetts Department of Public Health, Division of Epidemiology and Immunization. Guide to Surveillance, Reporting and Control. Boston: Massachusetts Department of Public Health; January 2001. 2006 edition available at: http://www.mass.gov/dph/cdc/gsrman. Accessed May 2, 2007.

20. Pertussis-United States, 1997-2000. MMWR Morb Mortal Wkly Rep 2002; 51:73-76.

21. National Immunization Program. Guidelines for the control of pertussis outbreaks. Atlanta, GA: Centers for Disease Control; 2000 (Amendments made in 2005 and 2006). Available at: http://www.cdc.gov/nip/ publications/pertussis/guide.htm. Accessed May 2, 2007.

22. Kretsinger K, Broder KR, Cortese MM, et al.; Centers for Disease Control and Prevention; Advisory Committee on Immunization Practices; Healthcare Infection Control Practices Advisory Committee. Preventing tetanus, diphtheria, and pertussis among adults: use of tetanus toxoid, reduced diphtheria toxoid and acellular pertussis vaccine recommendations of the Advisory Committee on Immunization Practices (ACIP) and recommendation of the ACIP, supported by the Healthcare Infection Control Practices Advisory Committee (HICPAC) for the use of Tdap among health-care personnel. MMWR Morb Mortal Wkly Rep 2006; 55(RR-17):1-37. 